\title{
CONCEPÇÃO DE GESTANTES SOBRE O PARTO CESARIANO*
}

\author{
Fernanda Bittencourt ${ }^{1}$, João Batista Vieira² ${ }^{2}$ Ana Carla Campos Hidalgo de Almeida ${ }^{3}$
}

\begin{abstract}
RESUMO: A gestação e o parto são acontecimentos biossociais permeados por valores culturais, familiares e emocionais e envolvem crenças e mitos que influenciam na escolha da via de parto. Este estudo objetivou identificar os motivos que levam gestantes a optar pela cesariana, pesquisar a influência cultural e familiar na escolha da via de parto e investigar as orientações recebidas. Caracteriza-se como pesquisa descritiva de abordagem qualitativa; os dados foram coletados em 2012 por meio de entrevista semiestruturada com 20 gestantes de duas clínicas privadas e duas Unidades Básicas de Saúde. Os resultados apontaram a dor e a influência familiar e cultural como interferentes na escolha da via do parto. Para reverter o crescente número de cesáreas é necessário destacar a importância da ação educativa durante o pré-natal para que a gestante possa ser ouvida e esclarecida em suas dúvidas e temores.
\end{abstract}

DESCRITORES: Gravidez; Parto normal; Cesárea.

\section{PREGNANT WOMEN'S CONCEPTIONS REGARDING CAESAREAN BIRTH}

ABSTRACT: Pregnancy and birth are bio-social happenings permeated with cultural, family and emotional values, and involve beliefs and myths which influence the choice of means of birth. This study aimed to identify the reasons which lead pregnant women to opt for caesarean births, to research the cultural and family influence on the choice of the means of birth, and to investigate the advice received. It is characterized as descriptive research with a qualitative approach; the data was collected in 2012 through semi-structured interviews with 20 pregnant women in two private clinics and two Primary Health Care Centers. The results indicated pain and the family and cultural influences as influencing the choice as to the means of birth. To roll back the growing number of caesareans, it is necessary to emphasize the importance of educational action during the pre-natal consultations so that the pregnant woman may be heard and have her doubts and fears clarified. DESCRIPTORS: Pregnancy; Normal birth; Caesarean.

\section{CONCEPCIÓN DE GESTANTES SOBRE LA OPERACIÓN CESÁREA}

RESUMEN: La gestación y el parto son acontecimientos biosociales permeados por valores culturales, familiares y emocionales e involucran creencias y mitos que influencian en la elección de la vía de parto. Este estudio tuvo la finalidad de identificar los motivos de las gestantes para optar por la cesárea, investigar la influencia cultural y familiar en la elección de la vía de parto e investigar las orientaciones que estas mujeres tuvieron. Se caracteriza como investigación descriptiva de abordaje cualitativo; los datos fueron obtenidos en 2012 por medio de entrevista semiestructurada con 20 gestantes de dos clínicas particulares y dos Unidades Básicas de Salud. Los resultados apuntaron el dolor y la influencia familiar y cultural como factores que se interponen en la elección de la vía del parto. Para reverter el creciente número de cesáreas, es necesario destacar la importancia de la acción educativa durante el prenatal para que la gestante pueda ser comprendida y para que sus dudas y miedos sean aclarados. DESCRIPTORES: Embarazo; Parto normal; Operación cesárea.

*Artigo extraído do Trabalho de Conclusão de Curso de Enfermagem apresentado à Pontifícia Universidade Católica do Paraná PUCPR, campus Toledo, em 2012 e intitulado "Cesariana: A Concepção das Gestantes em um Município do Paraná"

${ }^{1}$ Enfermeira.

${ }^{2}$ Enfermeiro da Secretaria Municipal de Saúde de Cascavel-Paraná.

${ }^{3}$ Enfermeira. Mestre em Enfermagem. Professora do Departamento e Coordenadora do Curso de Graduação em Enfermagem da PUCPR. 


\section{INTRODUÇÃO}

A gestação e o parto são acontecimentos que se distanciam de atos meramente biológicos, uma vez que são processos sociais que refletem valores culturais de uma sociedade imersa em aspectos político-econômicos, que se modificam entre cada sociedade e com o decorrer do tempo, interferindo na afinidade que a mulher terá em relação às vias de parto ${ }^{(1)}$.

Partindo dessa premissa, a história da obstetrícia passou por modificações de acordo com as características e disposições da sociedade de cada época. $\mathrm{O}$ parto na antiguidade era assistido por parteiras e feiticeiras baseado em crendices e sem cientificismo; dessa maneira, o cuidado obstétrico ocorria no contexto domiciliar sendo realizado por mulheres da família, amigas e vizinhas ${ }^{(2)}$. Esse processo natural, privativo e familiar, passou ao longo dos anos a ser vivenciado em instituições públicas e privadas de saúde. Assim, a institucionalização do parto favorece a submissão da mulher; ela perde sua autonomia, é separada da família e fica submetida a normas institucionais e práticas intervencionistas, sem o devido esclarecimento e consentimento ${ }^{(3-4)}$.

Não há duvidas de que a cesariana pode salvar vidas e prevenir sequelas neonatais; no entanto, a elevada incidência de cesárea no mundo vem tornando-se um grave problema de saúde pública e obstétrico. As consequências deste cenário podem ser graves, levando a maiores chances da mulher desenvolver infecção puerperal, risco de mortalidade e morbidade materna, e de prematuridade e mortalidade neonatal, recuperação mais difícil da puérpera, maior período de separação entre mãe e bebê, levando a atraso e dificuldade de lactação, e maior tempo de hospitalização, o que gera elevação de gastos para o sistema de saúde $e^{(3,5)}$.

É necessário, portanto, investigar as causas que levam ao aumento das taxas de cesarianas, que a partir do conhecimento, poderão ser desenvolvidas estratégias para que se modifique essa tendência. Diante dessas considerações, decidiu-se pela realização deste estudo, que teve por objetivos investigar os motivos que levam a mulher a optar pela cesariana, conhecer as crenças e os fatores culturais que se sobressaem durante a gestação e que podem influenciar na escolha da via de parto, e investigar quais orientações as gestantes tiveram sobre os diferentes tipos de parto, a fim de compreender a atual tendência de partos cirúrgicos realizados no município do estudo.

\section{MÉTODO}

Para elaboração desse estudo, optou-se pelo método descritivo, com abordagem qualitativa, na qual procura-se entender os fenômenos, segundo a perspectiva dos participantes da situação estudada, buscando a interpretação desses fenômenos ${ }^{(6)}$. Participaram da pesquisa 20 gestantes, usuárias dos serviços de saúde de duas clínicas privadas de obstetrícia e de duas Unidades Básicas de Saúde (UBS) no Município de Toledo-Paraná no primeiro trimestre de 2012.

Os critérios de inclusão das participantes foram: gestantes maiores de 18 anos, independente da renda e do nível de escolaridade e do período gestacional, que não apresentavam patologia pré-existente, que aceitaram participar voluntariamente do estudo, assinaram o termo e estavam presentes no local da pesquisa durante a coleta de dados. $O$ projeto foi submetido à apreciação pelo Comitê de Ética e Pesquisa em Seres Humanos da Pontifícia Universidade Católica do Paraná, recebendo parecer favorável para sua realização em 02 de março de 2011, sob o parecer n. 0004751/11 e Protocolo CEP n. 5833.

A abordagem das gestantes ocorreu em ambiente privativo, anteriormente às consultas de pré-natal, sem a presença do médico na sala. Primeiramente as respostas foram registradas por meio de gravador de voz que depois foram transcritas. Foi utilizada entrevista semiestruturada com utilização de um roteiro com duas etapas; na primeira parte constavam características sócioeconômicas e obstétricas referentes às gestações e partos anteriores; e a segunda contemplava questões referentes à escolha pela via de parto e orientações recebidas no pré-natal, sobre as vantagens e desvantagens do parto vaginal e da cesariana. Os dados obtidos passaram por um processo de análise do conteúdo seguido de análise temática.

Buscando preservar a identidade das participantes, não foi contextualizado referência que designe nominalmente a gestante de cada entrevista, estas foram identificadas na medida em que foram aparecendo no texto apenas como gestante 1 , gestante 2 , e assim sucessivamente.

\section{RESULTADOS}

Participaram do estudo 20 gestantes, com idade que variou de 18 a 35 anos e média de 27 anos. A média de idade gestacional obstétrica foi de 31 semanas, sendo a mínima de 16 e a máxima de 40 semanas. Em relação ao estado civil, $12(60 \%)$ eram casadas, $7(35 \%)$ amasiadas e uma (5\%) solteira. 
Em relação à escolaridade, todas as gestantes haviam, completado, ao menos o ensino fundamental; destas nove (45\%) relataram possuir curso superior ou estar cursando e uma relatou possuir curso de especialização. Das 20 gestantes, dez $(50 \%)$ ) referiram exercer atividade remunerada; oito $(40 \%)$ eram do lar ou estavam desempregadas e duas $(10 \%)$ relataram ser estudantes. Entre as gestantes que exerciam alguma atividade remunerada, a renda familiar variou de um salário e meio a 16 salários mínimos; oitro (40\%) não possuíam renda; uma $(5 \%)$ recebia pensão e uma (5\%) contava com o auxílio do benefício bolsa família.

Quanto à paridade, 60\% das entrevistadas relataram não ter filhos. Dentre as que já tinham filhos, o número mínimo foi de um e o máximo de seis filhos, perfazendo média de 1,75 filhos/mulher. O número de gestações variou de 1 a 5 , com média de 1,8; dez (50\%) eram primigestas; das demais, três (15\%) referiram aborto e uma (5\%) referiu gestação gemelar.

Quando questionadas sobre a existência de alguma intercorrência na gestação ou patologias de base pré-existentes, tais como, hipertensão arterial, diabetes gestacional, infecções, cardiopatias ou nefropatias, 19(95\%) negaram a ocorrência e somente uma (5\%) referiu doença hipertensiva específica da gestação, o que não a excluiu do estudo uma vez que o quadro hipertensivo ocorreu em função da gestação atual, não caracterizando assim patologia pré-existente. No que se refere a via escolhida para os partos anteriores, cinco $(25 \%)$ relataram ter realizado parto cesáreo, três $(15 \%)$ optaram pela via vaginal e $12(60 \%)$ negaram partos anteriores.

Entre as participantes, $18(90 \%)$ eram domiciliadas na cidade onde foi realizado o estudo; destas $16(80 \%)$ residiam em bairros do município e duas $(10 \%)$ possuíam seus domicílios no centro da cidade. Já duas (10\%) referiram residir em municípios vizinhos, porém realizavam o pré-natal em uma das clínicas do município onde foi realizada a pesquisa.

Em relação à preferência pela via de parto para a gestação atual, 11(55\%) das gestantes referiram desejar o parto cesáreo, das quais cinco $(25 \%)$ eram usuárias dos serviços privado de saúde e seis $(30 \%)$ da rede pública. O desejo de parto normal por sua vez foi citado por seis $(30 \%)$ das gestantes como forma de parturição, destas três (15\%) eram da rede privada e a mesma proporção utilizavam os serviços oferecidos pelo Sistema Único de saúde (SUS) em duas Unidades Básica de Saúde local. Já as que não fizeram ainda sua escolha totalizam $15 \%$ das entrevistadas.
Dentre os motivos expressos pelas 11 gestantes para optar pela cesariana, nove citaram medo do parto normal; destas, oito também referiram como motivo o histórico familiar de parto vaginal mal-sucedido e trabalho de parto demorado e exaustivo. Uma gestante optou pela intervenção cirúrgica pela praticidade de escolher a data de nascimento de seu filho e uma manisfestou o desejo de realizar a laqueadura tubárea oportunamente.

Da mesma forma, entre as nove que preferiram a via vaginal como opção de parto, cinco citaram como motivo a rápida recuperação e, entre essas, três também optaram por entenderem ser mais saudável para mãe e bebê. Uma gestante referiu que o parto normal oferece menor risco de hemorragia e de infecção.

Apesar de dez (50\%) das gestantes, do serviço público e privado, afirmarem ter recebido algum tipo de orientação, sobre os tipos de parto, esse achado configura-se como falta de informação sobre as vantagens e desvantagens desta via. Ou seja, embora as gestantes confirmem ter recebido, em algum momento, orientações, ao serem questionadas sobre as vantagens e desvantagens das diferentes vias de parto, as participantes não conseguiram expô-las, ainda, as gestantes informaram que as orientações foram dadas pelo obstetra, por professores universitário e/ou foram adquiridas em palestras, livros e meios de comunicação.Nenhuma gestante citou o profissional enfermeiro como educador e orientador em saúde.

A partir do discurso, da disposição e dos termos utilizados pelas entrevistadas, buscou-se contextualizar os resultados obtidos, organizando-os em três unidades temáticas: A influência cultural e familiar na escolha da via de parto; Parto normal como sinônimo de dor e sofrimento; Falta de orientações no pré-natal como fator determinante para a escolha do tipo de parto.

\section{DISCUSSÃO}

\section{A influência cultural e familiar na escolha da via de parto}

Ao envolver aspectos biológicos, psicológicos, sociais, culturais, entre outros, o parto é considerado como um fenômeno cercado de mitos e crenças, que são influenciados por diversos fatores, como medo, informações distorcidas recebidas, experiências de gestações anteriores, e por influência médica ${ }^{(1)}$.

Neste sentido, com relação a possíveis influências de opiniões e relatos de outras pessoas a respeito das 
vias de parto, as gestantes confirmaram que as mulheres mais próximas, sejam familiares ou amigas, tem papel fundamental e muitas dessas opiniões se perpetuam na sociedade ao serem passadas de mulher para mulher ${ }^{(7)}$.

Portanto, aspectos sócioeconômicos, tais como nível econômico, educação, informação, acesso aos serviços de saúde, juntando-se a fatores culturais, entendidos aqui como o complexo dos padrões de comportamento, das crenças e valores familiares transmitidos coletivamente que se modificam entre cada sociedade e com o decorrer do tempo, interferem e talvez determinem a afinidade que a mulher terá em relação ao parto normal e a cesariana ${ }^{(1)}$.

Buscando outras explicações que justifique a influência histórica, familiar e cultura, pesquisadores ${ }^{(3)}$ acrescentam que a expectativa em relação ao parto está ligada a experiências vividas culturalmente por essas gestantes, tais como cursos de preparação para gestantes, história obstétrica anterior, experiência pessoal ou familiar, que essa mulher tem em relação aos diferentes tipos de parto.

A influência familiar como determinante para a escolha da via de parto fica explícita nas falas das gestantes:

Pelo histórico da família [...] prefiro cesárea para não sentir dor, na minha família muitos sofreram, demora muito para ter [...], minha vó que sentiu muita dor que foi dificil [...]. (Gestante 02)

Histórico familiar, na verdade minha mãe teve muito problema no parto normal, ai prefiro cesariana. Ela teve dilatação insuficiente, ela teve três parto normal e uma cesariana, ela sofreu muito menos na cesariana [...] do que nos partos normais. (Gestante 04)

Essa verificação vem confirmar o que a literatura mostra, a cultura e a herança familiar influenciam nos fatores emocionais contribuindo para o medo e a angustia relacionada a gestação e a parturição ${ }^{(3)}$.

$\mathrm{Na}$ entrevista, durante a fala das gestantes, ficou evidente a influência que a família possui sobre a decisão desta em relação à escolha da via de parto. Essa escolha está diretamente ligada à experiência vivida culturalmente. Mulheres que relataram histórico de parto vaginal bem sucedido na família referem a escolha desta via para dar a luz ao concepto que está gestando; por outro lado, aquelas que relataram trabalho de parto vaginal longo, exaustivo e cercado de dor, são categóricas em optarem pela cesariana.

Neste sentido, acreditamos que além das consultas de pré-natal preconizadas pelo Ministério da Saúde, a existência e a prática de cursos de preparação para gestantes são de suma importância durante este período. É nestes que o profissional enfermeiro, devidamente capacitado, terá a oportunidade de atuar como agente transformador buscando mudar o cenário atual das "cesarianas a pedido", difundindo a via vaginal como opção mais saudável e segura.

\section{Parto normal como sinônimo de dor e sofrimento}

Entre os fatores que podem afetar a decisão da mulher quanto à escolha da via de parto está o medo da dor na hora do trabalho de parto e parto, o que leva gestantes a optarem pela cesárea eletiva, na busca de um parto menos doloroso. Isto equivale a dizer que $o$ medo do parto pode ser considerado a expressão de sentimentos de ansiedade alimentados durante a gestação e que está vinculado com a elevação do risco de uma experiência negativa ${ }^{(3)}$.

A questão do medo e a dor durante o parto foi expressa tanto pelas gestantes usuárias da rede pública como pelas da rede particular de atenção à saúde obstétrica. As colocações feitas pelas gestantes ilustram, de maneira significativa, o medo da dor e sua correlação com o parto, e de maneira especial com o parto normal:

[...] por medo, por dor, por não sentir dor, tudo isso [...], prefiro cesárea para não sentir dor. Na minha família, muitos sofreram, demora muito para ter, essas coisas. Assim, tenho medo de sentir dor. (Gestante 02)

\section{[...] o parto normal é mais dolorido, [...] eu já marquei a cesárea. (Gestante 03 )}

Por medo do parto normal e por ver a experiência de outras mulheres que não ficaram satisfeitas com o parto normal e medo mesmo na hora do parto dar algum problema no bebê, uma intercorrência. (Gestante 13)

Porque é mais calmo assim, não precisa sofrer tanto, eu acho que no partonormal a gentesofremais. (Gestante 11)

Assim, encontramos o medo como um fator sócio-cultural que contribui de maneira significante para o aumento do número de cesáreas. $\mathrm{O}$ temor, materializado nas falas das gestantes, se mostra presente durante o ciclo gestacional, chegando até o momento do parto 
e mesmo no pós-parto ${ }^{(1)}$.

Neste sentido, o parto passou a ser vivenciado como um momento de intenso sofrimento físico e psicológico. O medo, a tensão e a dor das parturientes impedem o processo fisiológico do parto normal, o que acarreta em práticas intervencionistas, que na maioria das vezes poderiam ser evitadas ${ }^{(8)}$.

\section{Falta de orientações no pré-natal como fator deter- minante para a escolha do tipo de parto}

A assistência ofertada às gestantes durante o pré-natal busca acolhê-la desde a confirmação da gravidez até parto e puerpério, com o objetivo de acompanhar e evitar complicações materna/fetal. Contudo, para que $\mathrm{o}$ atendimento seja realizado, as gestantes precisam ter consciência da importância deste serviço e procurá-lo logo após a descoberta da gestação ${ }^{(9)}$. Nesse sentido, o pré-natal na sua essência se constitui como

um conjunto de procedimentos clínicos e educativos com o objetivo de promover a saúde e identificar precocemente os problemas que possam resultar em risco para a saúde da gestante e do concepto ${ }^{(10: 1594)}$.

Desta maneira, segundo parâmetros estabelecidos pelo Ministério da Saúde para garantir um pré-natal de qualidade, é preciso realizar no mínino seis consultas. Preferencialmente uma no primeiro trimestre, duas no segundo trimestre e três no terceiro trimestre da gestação. $\mathrm{O}$ aumento no número de consultas na fase final da gestação visa à avaliação do risco perinatal e materno buscando identificar precocemente situações de risco, para prevenir complicações como o trabalho de parto prematuro, doença hipertensiva específica da gestação e a diabetes gestacional ${ }^{(11)}$.

Teoricamente, é no pré-natal que os profissionais de saúde promovem a troca de informações a cerca das vias de parto, buscando estabelecer as diferenças existentes entre elas e identificando as vantagens e as desvantagens do parto vaginal em relação ao parto cesáreo. Além disso, é de suma importância o apoio emocional, a fim de garantir à mulher o bem estar durante a gestação, parto e puerpério; bem como contribuir para reduzir a ansiedade, a insegurança e o medo do parto ${ }^{(9)}$.

Neste sentido, buscando contribuir com a discussão, autores acrescentam que há pouca ou nenhuma informação/orientação durante o pré natal sobre as verdadeiras indicações da cesariana e os benefícios e desvantagens de cada tipo de parto, associado ao avanço tecnológico - no que se refere as técnicas cirúrgicas - caracterizam um modelo assistencial médico determinante para a ascensão do parto cirúrgico ${ }^{(12)}$.

Pelos depoimentos a seguir, pode-se observar que durante as consultas no pré-natal muitas dúvidas não foram esclarecidas e muitas informações de extrema importância foram deixadas de serem mencionadas:

[...] quando passa a pensar em engravidar [...] você passa a interessar mais sobre o assunto né, aí acabei lendo algumas coisas a respeito e também na $T V$, vira e mexe, passa alguma matéria a respeito. Mas, com profissionais de saúde nunca. (Gestante 15)

Não recebi [informação], a hora que eu disse para o médico que eu queria cesariana ele aceitou e falou que mais pro final da gestação a gente conversaria sobre data. Não é nem enfermeira nem médico, nunca ninguém falou nada sobre o parto normal, as vantagens e desvantagens não. (Gestante 13)

O fato curioso e de certa forma preocupante é que dentre as gestantes que relataram terem recebidos algum tipo de orientação, as mesmas foram dadas pelo seu obstetra, por professores universitários e/ou foram adquiridos por meio de palestras, livros e de meios de comunicação como a televisão e a internet. Nenhuma das pesquisadas, tanto da rede pública como da rede privada, citou o profissional enfermeiro como orientador e educador em saúde, confirmando o vazio da assistência de enfermagem nesta área de atuação.

Este vazio foi identificado nos locais onde a pesquisa foi realizada, nas clínicas particulares não consta, em seu quadro de colaboradores, o profissional enfermeiro, ficando a assistência prestada no período gravídico e puerperal a cargo, exclusivamente, do médico obstetra. Já nas Unidades Básicas de Saúde existe o profissional enfermeiro, porém sua atuação, em relação à assistência obstétrica, se limita apenas em realizar o cadastro das gestantes, solicitar exames referentes ao primeiro trimestre de gestação e orientar as gestantes que eventualmente os procuram.

Ressalta-se que nas Unidades Básicas de Saúde, quem faz o acompanhamento do pré-natal é o profissional de enfermagem, desde que a gestante não apresente gravidez de risco. Essa competência é atribuída de maneira privativa ao enfermeiro na Lei do Exercício Profissional da Enfermagem - Decreto n. 94.406/87 "apontando que o pré-natal de baixo risco pode ser inteiramente acompanhado pela enfermeira"(13:18). 


\section{CONSIDERAÇÕES FINAIS}

Os resultados revelaram a preferência de mulheres pelo parto cirúrgico vindo corroborar com os altos índices de cesáreas registrados, atualmente, no Brasil. Constatamos que o medo e a dor, a influência cultural e familiar, e o desejo em realizar a laqueadura tubária são fatores determinantes na escolha da cesárea.

A escassez de informações à gestante colabora para a escolha do parto cesáreo. Ressalta-se a necessidade de desenvolver educação ativa para o esclarecimento da população sobre os benefícios e as desvantagens das vias de parto.

Ficou evidente a necessidade da ação educativa a ser realizada pelo enfermeiro durante o pré-natal a fim de resgatar o papel ativo da mulher no processo parturitivo, para que esta não seja induzida nem coagida na escolha da preferência do tipo de parto, bem como ser ouvida e esclarecida em suas dúvidas e temores.

\section{REFERÊNCIAS}

1. Camara MFB, Medeiros M, Barbosa MA. Fatores sócioculturais que influenciam a alta incidência de cesáreas e os vazios da assistência de enfermagem. Rev. Eletr. Enf. [Internet] 2000;16(1) [acesso em 17 abr 2012]. Disponível: http://www.fen.ufg.br/revista/revista2_1/ Cesarea.html.

2. Salim NR, Soares GCF, Brigagão JI, Gualda DMR. Os sentidos do cuidado no parto: um estudo intergeracional. Cogitare enferm. [Internet] 2012;17(4) [acesso em 19 mar 2013]. Disponível: http://ojs.c3sl.ufpr.br/ojs2/index. php/cogitare/article/viewFile/30358/19647.

3. Gonçalves AK, Missio L. Fatores determinantes para as expectativas de gestantes acerca da via de parto. In: $7^{\circ}$ Encontro de Iniciação Científica. [Internet] Dourados: UEMS; 2009. [acesso em 28 jan 2012]. Disponível: http://periodicos.uems.br/index.php/enic/ article/view/1978.

4. Rezende J. Obstetrícia. 11 ${ }^{\mathrm{a}}$. ed. Rio de Janeiro: Guanabara Koogan; 2009.

5. Dodd JM, Crowther CA, Hiller JE, Haslam RR, Robinson JS. Birth after caesarean study: planned vaginal birth or planned elective repeat caesarean for women at term with a single previous caesarean birth: protocol for a patient preference study and randomised trial. BMC Pregnancy and Childbirth. [Internet] 2007;7(7) [acesso em 10 mai 2012]. Disponível: http://www.biomedcentral. com/1471-2393/7/17.doi:10.1186/1471-2393-7-17.
6. Neves JL. Pesquisa qualitativa: características, uso e possibilidades. Cad. pesq. adm. [Internet] 1996;1(3) [acesso em 13 mar 2012]. Disponível: www.ead.fea. usp.br/cad-pesq/arquivos/c03-art06.pdf.

7. Figueiredo NSV, Barbosa MCA, Silva TAS, Passarini TM, Lana BN, Barreto J. Fatores culturais determinantes da escolha da via de parto por gestantes. Rev. HU. [Internet] 2010;36(4) [acesso em 13 mar 2012]. Disponível: http://www.seer.ufjf.br/index.php/ hurevista/article/viewFile/1146/460.

8. Organização Mundial da Saúde (OMS). Assistência ao parto normal: um guia prático: relatório de um grupo técnico. Genebra: OMS; 1996.

9. Soares DMD, Sedrez ES, Leal AF, Peres MCN, Ludtke I. Influência do pré-natal na escolha do tipo de parto: avaliação de gestantes que realizaram o pré natal em uma unidade básica de saúde de um bairro no interior da cidade de Pelotas. In: $18^{\circ}$ Congresso de Iniciação Científica. [Internet]. Pelotas: UFPEL; 2009 [acesso em 12 fev 2012]. Disponível: http://www.ufpel.edu.br/ cic/2009/cd/pdf/CS/CS_01206.pdf.

10. Ministério da Saúde (BR). Assistência Integral à Saúde da Mulher: Bases de Ação Programática. [Internet] [acesso em 19 abr 2012]. Disponível: http://bvsms.saude. gov.br/bvs/publicacoes/assistencia_integral_saude_ mulher.pdf.

11. Ministério da Saúde (BR). Secretaria de Atenção à Saúde. Departamento de Ações Programáticas Estratégicas. Área Técnica de Saúde da Mulher. Prénatal e Puerpério: atenção qualificada e humanizada. Brasília: Ministério da Saúde. [Internet] 2005-2006 [acesso em 19 abr 2012]. Disponível: http://portal.saude. gov.br/portal/arquivos/pdf/manual_puerperio_2006. pdf.

12. Fabri RH, Murta EFC. Tipos de Parto e Formas de Assistência Médica em Uberaba-MG. Rev. Bras. Ginecol. Obstet. [Internet] 1999;21(2):1-5 [acesso em 19 abr 2012]. Disponível: http://dx.doi.org/10.1590/S010072031999000200007

13. Ministério da Saúde (BR). Assistência pré-natal: manual técnico. [Internet]. $3^{\mathrm{a}}$ ed. Brasília, DF: Secretaria de Políticas de Saúde - SPS/Ministério da Saúde; 2000. [acesso em 19 abr 2012]. Disponível: http://bvsms.saude. gov.br/bvs/publicacoes/cd04_11.pdf. 